\title{
A retrospective molecular analysis of gentamicin resistance in Staphylococcus aureus strains from UK hospitals
}

\author{
C. L. WRIGHT**, M. E. BYRNE*\&, N. FIRTH† and R. A. SKURRAY*† \\ * Department of Microbiology, Monash University, Clayton, Victoria 3168 and †School of Biological Sciences, \\ University of Sydney, Sydney, New South Wales 2006, Australia
}

\begin{abstract}
The composite transposon $T \mathbf{n} 4001$, and a related chromosomal Tn4001-like element, encode resistance to the aminoglycosides gentamicin, tobramycin and kanamycin $\left(\mathbf{G m T m K m} \mathbf{m}^{\mathrm{r}}\right)$ in Australian strains of Staphylococcus aureus. Southern hybridisation analysis of $\mathrm{GmTmKm}^{\mathrm{r}} S$. aureus strains isolated from various hospitals in the UK between 1975 and 1985 indicated that they predominantly encoded chromosomal copies of Tn4001 or a Tn4001-like element. However, a strain isolated in 1985 was found to carry Tn4001 on a plasmid related to pSK1, the prototypical multiresistance plasmid commonly detected in $S$. aureus strains from Australian hospitals.
\end{abstract}

\section{Introduction}

Since the mid-1970s, nosocomial strains of Staphylococcus aureus resistant to gentamicin and the related aminoglycosides, tobramycin and kanamycin (GmTm$\mathrm{Km}^{\mathrm{r}}$ ) have been isolated in many parts of the world, including Europe [1-4], North America [5, 6] and Australia $[7,8]$. In $S$. aureus, $\mathrm{GmTmKm}^{\mathrm{r}}$ has generally been found to be mediated by a bifunctional enzyme that specifies $6^{\prime}$-acetyltransferase $\left[\mathrm{AAC}\left(6^{\prime}\right)\right]$ and $2^{\prime \prime}$ phosphotransferase $\left[\mathrm{APH}\left(2^{\prime \prime}\right)\right]$ aminoglycoside modifying activities $[9,10]$.

In strains of $S$. aureus from Australian hospitals, $\mathrm{GmTmKm}^{\mathrm{r}}$ has most often been reported to be encoded on the $4.5-\mathrm{kb}$ transposon $\mathrm{Tn} 4001$ that is composed of a 1.9-kb central region flanked by inverted copies of the $1.3-\mathrm{kb}$ insertion element IS 256 [11-14]. The central region of $\operatorname{Tn} 4001$ carries an aacA-aphD gene which mediates $\mathrm{GmTmKm}^{\mathrm{r}}$ via production of the $\mathrm{AAC}\left(6^{\prime}\right)-\mathrm{APH}\left(2^{\prime \prime}\right)$ bifunctional enzyme [15].

Gentamicin resistance in Australian $S$. aureus isolates

Received 11 April 1997; accepted 16 June 1997

Corresponding author: Professor R. A. Skurray.

†Present address: CSIRO Division of Animal Health, Parkville, Victoria 3052, Australia.

§Present address: Cold Spring Harbor Laboratories, PO Box 100, Cold Spring Harbor, NY 11724, USA. was first reported in 1976 [7]. In $\mathrm{GmTmKm}^{\mathrm{r}}$ strains isolated between 1976 and 1980, Tn4001 or a related Tn4001-like element were detected at various chromosomal sites [8, 16, 17]. This Tn4001-like element is composed of an entire Tn4001 with an additional $1.7 \mathrm{~kb}$ segment of DNA located in the central region [16 and C.L. Wright, A. Hettiaratchi, N. Firth and R. A. Skurray, unpublished observations].

In most methicillin- and gentamicin-resistant $S$. aureus strains isolated in Australia since 1980 - the so-called 'classic' or 'epidemic' Australian MRSA-Tn4001 has been located on a group of structurally related, multiresistance plasmids, designated the pSK1 family $[12,16,18,19]$. Plasmids of this family typically carry the qacA multidrug resistance gene which encodes resistance to various antiseptics and disinfectants $[20,21]$. In addition, members of the pSK1 family of plasmids may confer resistance to trimethoprim encoded on the transposon-like structure Tn4003 [22, 23] and penicillin via the transposon $\operatorname{Tn} 4002$ [24].

Some epidemic methicillin- and gentamicin-resistant $S$. aureus strains isolated in UK hospitals carry plasmids that appear to be members of the pSK1 family and encode $\mathrm{GmTmKm}^{\mathrm{r}}$ on $\operatorname{Tn} 4001[25,26]$, whereas others possess chromosomal copies of Tn4001 [27]. A retrospective analysis of $S$. aureus strains isolated from hospitals in the UK between 1966 and 1986 was carried out to ascertain the involvement of Tn4001 and Tn4001-like elements in the emergence of $\mathrm{GmTmKm}$. 


\section{Materials and methods}

\section{Bacterial strains and plasmids}

The $S$. aureus strains were isolated from various UK hospitals between 1966 and 1986 and held in a collection at the Laboratory of Hospital Infection, Central Public Health Laboratory, Colindale, London. The gentamicin-resistant strains and their relevant characteristics are listed in Table 1.

S. aureus strains used as controls included the rifampicin- and novobiocin-resistant laboratory strain SK982 [11], and the Australian GmTmKm ${ }^{\mathrm{r}}$ clinical strains SK529, SK1717 and SK1774. S. aureus SK529 carries the plasmids pSK1, pSK2 and pSK3 [17]; strains SK1717 and SK1774 carry chromosomal copies of Tn4001 and a Tn4001-like element, respectively [16].

The Escherichia coli plasmid pSK310, consisting of the $2.5-\mathrm{kb}$ HindIII fragment of Tn4001 from pSK1 cloned into the HindIII site of pACYC184 [12], was used to obtain the 1.3-kb HindII-TaqI Tn4001-specific probe.

\section{General methods}

Standard culture media, methods for determining antimicrobial susceptibilities and minimum inhibitory concentrations (MICs) of antibiotics, mixed culture transfer and plasmid elimination procedures were as described previously [8, 17].

\section{Molecular analysis}

Isolation of whole-cell DNA from $S$. aureus, digestion with restriction endonucleases, agarose gel electrophoresis and Southern hybridisation were performed as described by Lyon et al. $[12,17]$. E . coli plasmid DNA was isolated by standard methods [28]. DNA for use as a radiolabelled probe was electro-eluted from an agarose gel and nick translated with $\left[\alpha-{ }^{32} \mathrm{P}\right]$ dATP [28].

\section{Results}

\section{Characterisation of $U K \mathrm{GmTmKm}{ }^{r}$ S. aureus strains}

Of $74 \mathrm{~S}$. aureus strains isolated from various hospitals in the UK between 1966 and 1986, inclusive, 19, all isolated in the period from 1975 to 1985 , were found to encode $\mathrm{GmTmKm}$; many of these strains, particularly those isolated after 1978, showed resistance to other antimicrobial agents (Table 1).

Agarose gel electrophoresis of whole-cell DNA isolated from 10 strains representative of the 19 $\mathrm{GmTmKm}^{\mathrm{r}} S$. aureus isolates is shown in Fig. Ia (lanes $\mathrm{e}-\mathrm{n}$ ). Whole-cell DNA from the Australian clinical $\mathrm{GmTmKm}^{\mathrm{r}}$ isolate SK529 is also shown (Fig. 1a, lane b). This strain carries the multiresistance plasmid pSK1 $(28.4 \mathrm{~kb})$, the chloramphenicol resistance plasmid pSK2 $(4.5 \mathrm{~kb})$ and the cryptic plasmid pSK3 (1.5 kb) [17]. Fig. 2 shows a physical and genetic map of pSK1 with an expanded map of $\operatorname{Tn} 4001$ [29].

Each of the $19 \mathrm{GmTmKm}^{\mathrm{r}}$ UK strains, except for $S$. aureus SK3738 (Fig. 1a, lane m), carried up to three plasmids of various sizes. Nine strains including $S$. aureus SK3715, SK3718, SK3727, SK3735 and SK3763 (Fig. 1a, lanes e, f, i, k and n, respectively) and $S$. aureus SK3730, SK3739, SK3747, and SK3749 (data not shown) were found to carry plasmids $>20 \mathrm{~kb}$ in size.

Table 1. Characteristics of $\mathrm{GmTmKm}^{\mathrm{r}} S$. aureus strains

\begin{tabular}{|c|c|c|c|}
\hline Strain no. & Year isolated & Hospital & Additional resistance to \\
\hline SK3715* & 1975 & Westminster, London & Pc Ak Cd \\
\hline SK3718* & 1976 & St George's, London & Pc Ak Cd \\
\hline SK3720 & 1976 & St George's, London & Pc Tc Cd \\
\hline SK3721* & 1976 & Royal United, Bath & $\mathrm{Ak}$ \\
\hline SK3722 & 1977 & Royal United, Bath & $\mathrm{Ak}$ \\
\hline SK3723 & 1977 & School of Medicine, Leeds & $\mathrm{Pc}$ \\
\hline SK3724* & 1977 & Royal Infirmary, Glasgow & $\mathrm{Pc} \mathrm{Eb} \mathrm{Fa}$ \\
\hline SK3727* & 1977 & Edgware General, London & Pc $\mathrm{Tc} \mathrm{Em} \mathrm{Cd} \mathrm{Hg}$ \\
\hline SK3730 & 1978 & Withington, Manchester & Tc Em Nm Ak Tp \\
\hline SK3731* & 1978 & Royal Berkshire, Reading & Em \\
\hline SK3734 & 1979 & Withington, Manchester & Tc Em Nm Ak Tp Eb \\
\hline SK $3735^{*}$ & 1979 & Hillingdon, London & Mc Pc Tc $\mathrm{Em} \mathrm{Cl} \mathrm{Cm} \mathrm{Eb} \mathrm{Cd} \mathrm{Hg}$ \\
\hline SK3736 & 1979 & Southport General Infirmary & Tc Em Nm Ak Tp Eb \\
\hline SK3738* & 1980 & Southport General Infirmary & Pc Tc Em Nm Ak Tp \\
\hline SK3739 & 1980 & University College, London & $\mathrm{Mc} \mathrm{Pc} \mathrm{Tc} \mathrm{Em} \mathrm{Cm} \mathrm{Cd} \mathrm{Hg}$ \\
\hline SK3747 & 1982 & Southend, Essex & $\mathrm{Mc}$ Pc Tc Em Nm Ak Cl Tp \\
\hline SK3749 & 1982 & Whittington, London & $\mathrm{Mc} \mathrm{Pc}$ Tc Ak Eb Nv \\
\hline SK3754* & 1984 & Southend, Essex & $\mathrm{Mc} \mathrm{Pc} \mathrm{Tc} \mathrm{Em} \mathrm{Cl} \mathrm{Tp}$ \\
\hline SK3763* & 1985 & Leicester Royal Infirmary & $\mathrm{Mc} \mathrm{Pc} \mathrm{Tc} \mathrm{Em} \mathrm{Cl} \mathrm{Tp} \mathrm{Cd} \mathrm{Hg}$ \\
\hline
\end{tabular}

Ak, amikacin; $\mathrm{Cd}$, cadmium; $\mathrm{Cl}$, clindamycin; $\mathrm{Cm}$, chloramphenicol; Eb, ethidium bromide; $\mathrm{Em}$, erythromycin; Fa, fusidic acid; $\mathrm{Hg}$, mercury; Mc, methicillin; Nm, neomycin; Nv, novobiocin; Pc, penicillin; Tc, tetracycline; Tp, trimethoprim.

${ }^{*}$ Strains used in experiments described in Figs. 1,3 and 4. 


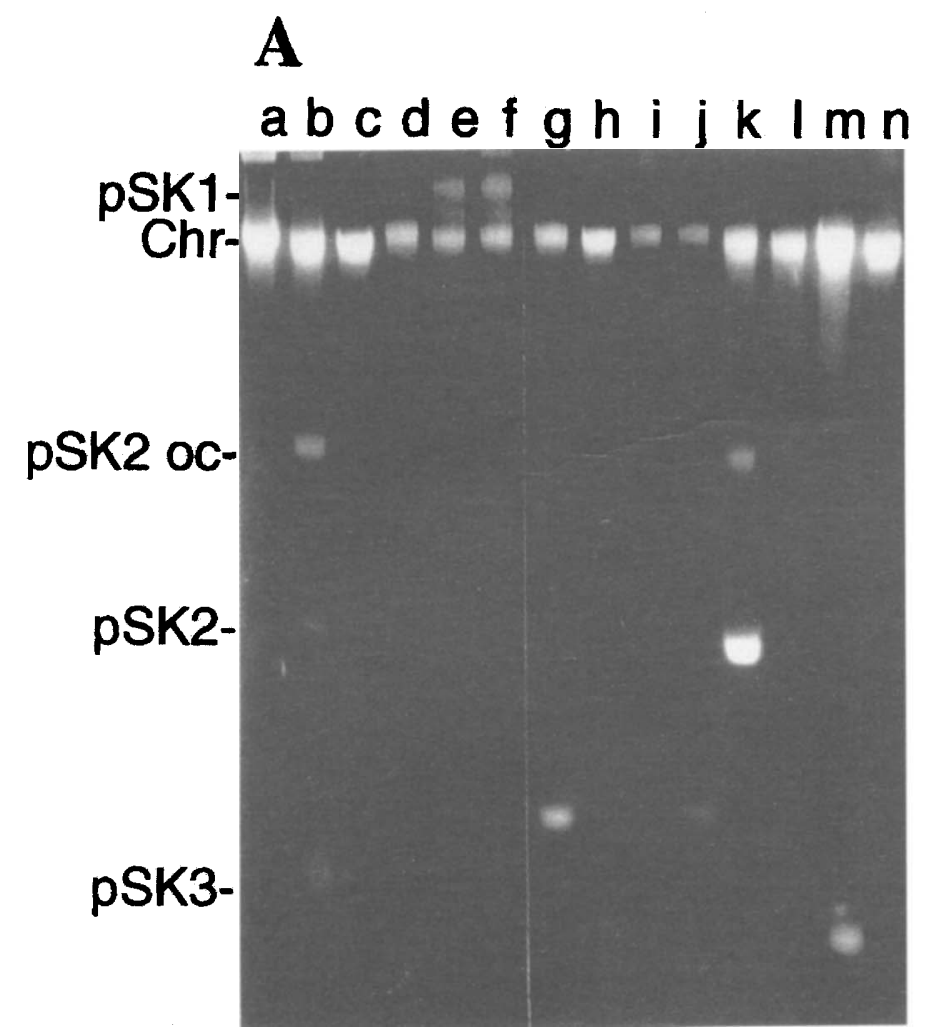

\section{B}

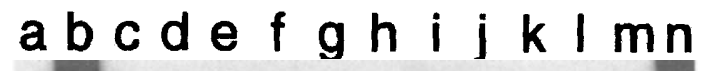

Fig. 1. (A) Agarose $(1.0 \% \mathrm{w} / \mathrm{v})$ gel electrophoresis of whole-cell $S$. aureus DNA: lane a, SK982, a gentamicinsensitive control strain; b, SK529; c, SK1717; d, SK1774; e, SK3715; f, SK3718; g, SK3721; h, SK3724; i, SK3727; j, SK3731; k, SK3735; 1, SK3738; m, SK3754; n, SK3763. The positions of the three plasmids pSK1, pSK2 and pSK3 found in the Australian $S$. aureus clinical strain, SK529 (lane b), are labelled; the open circular (oc) form of pSK2 is also indicated. The chromosomal band is labelled (Chr). (B) Autoradiograph of DNA from the above gel transferred to nitrocellulose and hybridised with an $\alpha-{ }^{32} \mathrm{P}$ nick-translated probe consisting of the 1.3-kb HindII-Taq I fragment of $\operatorname{Tn} 4001$.

\section{Detection of Tn4001 sequences in UK GmTmKm ${ }^{r}$ S. aureus strains}

Whole-cell DNA from all 19 strains was initially hybridised with a 1.3-kb HindII-Taq I fragment from Tn 4001 , which is specific for the central region of Tn 4001 that encodes the aacA-aphD gene (Fig. 2) [15, 16]. Fig. $1 \mathrm{~b}$ shows hybridisation of this probe to undigested whole-cell DNA from the gel in Fig. 1a. The probe did not hybridise to DNA of the gentamicinsensitive control, S. aureus SK982 (Fig. 1b, lane a), but did hybridise to DNA from the three Australian $\mathrm{GmTmKm}^{\mathrm{r}}$ strains: S. aureus SK529 (Fig. 1b, lane b), which carries Tn4001 on pSK1 [12]; S. aureus SK1717 (Fig. 1b, lane c), which carries a chromosomal copy of Tn4001; and S. aureus SK1774 (Fig. 1b, lane d), which carries a chromosomal copy of the Tn4001like element [16].

Of the UK strains examined, only S. aureus SK3763 possessed a plasmid, designated pSK575, which hybridised to the HindII-TaqI probe (Fig. 1b, lane n). With whole-cell DNA isolated from this strain and from S. aureus SK529 (Fig. 1b, lane b) there was also some hybridisation of the probe to DNA migrating at a position equivalent to that of the chromosome. $S$. aureus SK529 cured of pSK1 (SK553) and S. aureus
SK3763 cured of pSK575 (SK4009) were both $\mathrm{GmTmKm}^{\mathrm{s}}$, and whole-cell DNA of these two cured derivatives did not hybridise with the 1.3-kb HindIITaq I fragment of Tn4001. Thus, for S. aureus SK529 and SK3763, hybridisation of $\mathrm{Tn} 4001$ probe to DNA migrating at the level of the chromosome was probably due to the presence of contaminating plasmid DNA co-migrating with the chromosome.

In the other $18 \mathrm{GmTmKm}^{\mathrm{r}}$ strains the probe hybridised to a single band migrating at a position equivalent to that of the chromosome, as shown by the examples in Fig. 1b, lanes e-m.

To further compare the $\mathrm{GmTmKm}{ }^{\mathrm{r}}$ determinants in the UK strains with Tn4001, whole-cell DNA from the 10 strains shown in Fig. 1 was digested with HindIII and probed with the 1.3-kb HindII-Taq I fragment of Tn 4001 . Tn 4001 possesses a 2.5 -kb HindIII fragment which encompasses the aacA-aphD-encoding central region and $298 \mathrm{bp}$ of each flanking IS256 element (Fig. 2) $[14,15]$. As expected, the probe hybridised with a $2.5-\mathrm{kb}$ HindIII fragment from the Tn4001-carrying Australian S. aureus strains SK529 and SK1717 (Fig. 3, lanes $b$ and $c$ ). The probe also hybridised to an equivalently sized band in seven of the UK strains - 


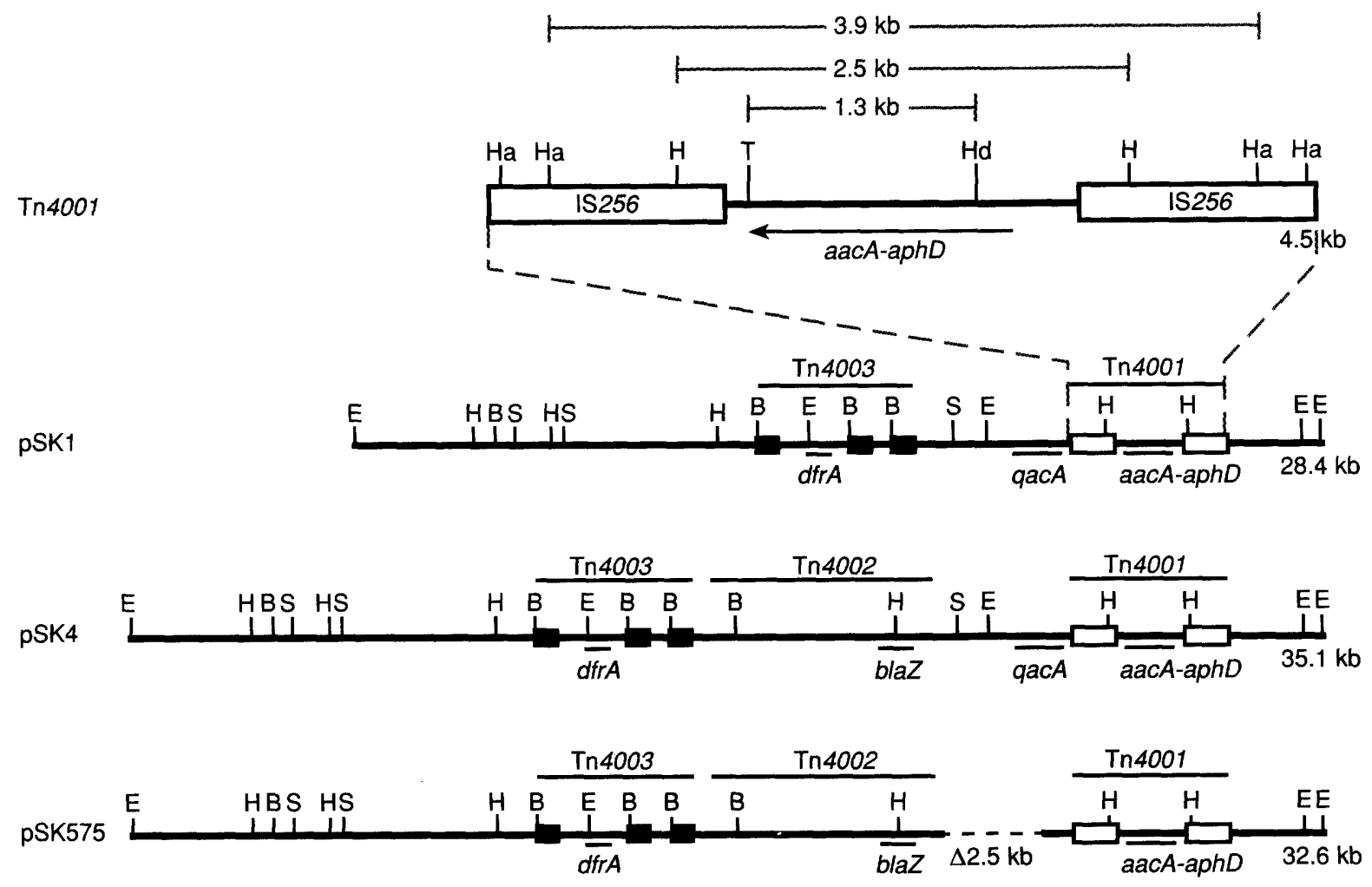

Fig. 2. Physical and genetic maps of plasmids pSK1 and pSK4 from $\mathrm{GmTmKm}^{\mathrm{r}}$ Australian strains of $S$. aureus [19] and pSK575 from the GmTmKm ${ }^{r}$ UK $S$. aureus strain SK3763. The sizes of the plasmids are indicated on the right. The three plasmids are aligned relative to the aacA-aphD gene of Tn 4001 which confers $\mathrm{GmTmKm}^{\mathrm{r}}$. An expanded map of $\mathrm{Tn} 4001$ shows relevant restriction sites and the extent of the 1.3-kb HindII-TaqI fragment from the aacA-aphDencoding central region which was used as a probe. The locations of the other determinants encoded by these plasmids are also shown. The qacA gene encodes multi-drug resistance to antiseptics and disinfectants; $d f r A$ encodes trimethoprim resistance and is located on the transposon-like structure $\mathrm{Tn} 4003$; and blaZ mediates penicillin resistance and is encoded on the transposon Tn4002. A dotted line indicates the approximate position of a $2.5-\mathrm{kb}$ segment absent from pSK575 in comparison to pSK4. Inverted copies of IS256 on Tn4001 and directly repeated copies of IS257 associated with $\mathrm{Tn} 4003$ are represented by $\square$ and $\mathbf{\square}$, respectively. Restriction sites are indicated by B, BglII; E, EcoRI; Ha, HaeIII; Hd; HindII; H, HindIII; S, SalI; T, TaqI; for clarity, only selected sites are shown.

\section{$a b c d e f g h$ i j k Imn}

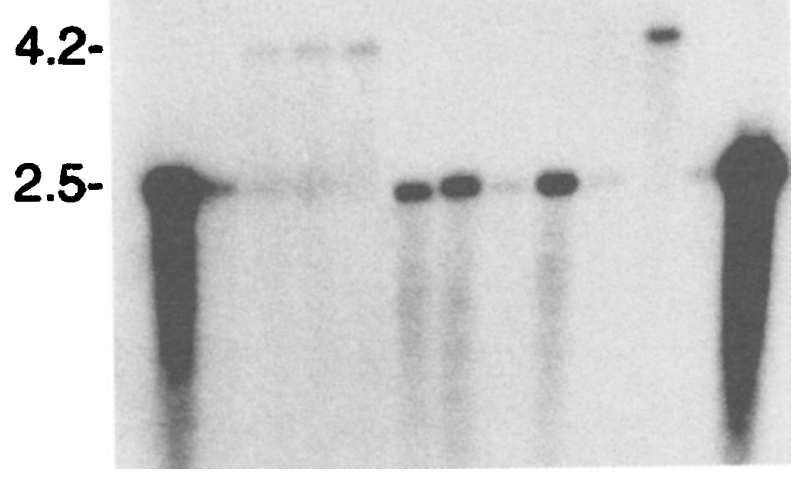

Fig. 3. Autoradiograph of whole-cell $S$. aureus DNA cleaved with HindIII and hybridised with $\alpha-{ }^{32} \mathrm{P}$ nicktranslated probe consisting of the 1.3-kb HindII-Taq I fragment of $\mathrm{Tn} 4001$. Fragments were separated by electrophoresis on an agarose $1.0 \% \quad \mathrm{w} / \mathrm{v}$ gel then transferred to nitrocellulose for hybridisation. Sizes (in $\mathrm{kb}$ ) of the two fragments found to hybridise with the probe are shown on the left. Lanes $\mathbf{a}-\mathbf{n}$ contain DNA from the same strains as those shown in Fig. 1.
S. aureus strains SK3721, SK3724, SK3727, SK3731, SK3735, SK3754 and SK3763 (Fig. 3, lanes g-k, m, n) - indicating the presence of $\operatorname{Tn} 400 \mathrm{I}$ on the plasmid pSK575 in S. aureus SK3763 and on the chromosome in the other six strains. In experiments in which whole-cell DNA was cleaved with Hae III and probed with the 1.3$\mathrm{kb}$ Hin dII-Taq I fragment of Tn4001, fragments equivalent to the $3.9-\mathrm{kb}$ Hae III fragment of Tn4001 (Fig. 2) hybridised with the probe in the seven UK strains described above (data not shown). Therefore, it is likely that these strains each carry an entire copy of Tn 4001 .

In contrast to the $2.5-\mathrm{kb}$ Tn 4001 HindIII fragment seen in the seven UK isolates described above, $S$. aureus strains SK3715, SK3718 and SK3738 were found to possess a 4.2-kb hybridising fragment (Fig. 3, lanes $e, f$ and 1) which corresponded to that of the larger Tn4001-like element carried in the chromosome of the Australian strain SK1774 (Fig. 3, lane d). As with $S$. aureus SK1774, Hae III digests of DNA from all three UK strains showed a fragment of $5.6 \mathrm{~kb}$ which hybridised to the Tn4001-specific probe, suggesting that these strains also carry the larger Tn4001-like element (data not shown). 
Diversity of chromosomal sites occupied by Tn4001 and the Tn4001-like element

Whole-cell DNA from the nine UK $S$. aureus strains described above and the two Australian strains SK1717 and SK1774, was digested with EcoRI, for which there are no sites in either Tn4001 or the Tn4001-like element [16]. These digests were probed with the 1.3kb HindII-TaqI fragment of Tn4001 (Fig. 4).

With each strain, the $a a c A-a p h D$ specific probe hybridised to only one chromosomal EcoRI fragment which ranged in size from 8 to $>20 \mathrm{~kb}$ (Fig. 4, lanes $\mathrm{c}-\mathrm{m}$ ), suggesting that each strain carries a single copy of either Tn 4001 or the Tn 4001 -like element, located at a variety of chromosomal sites.

\section{Characterisation of pSK1-family plasmid pSK575}

The Tn4001-specific probe also hybridised to $9.5-\mathrm{kb}$ and 18.5-kb fragments of plasmids pSK1 (Fig. 4, lane b) and pSK575 (Fig. 4, lane n), respectively. Transfer of plasmid pSK575 from S. aureus SK3763 to the laboratory strain SK982 by mixed culture transfer demonstrated that this plasmid encoded resistance to penicillin and trimethoprim as well as $G m T m K^{r}$. Plasmid pSK575 was found to possess a restriction endonuclease digestion profile very similar to that of the pSK1 family plasmid, pSK4 (Fig. 2) [19, 24], which mediates resistance to penicillin via a $\beta$ lactamase gene, blaZ, on Tn4002 [24] and resistance to trimethoprim encoded by a dihydrofolate reductase (DHFR) gene, dfrA on the transposon-like structure, Tn4003 [22, 23]. However, plasmid pSK575 appeared

\section{$a b c d e f g h i j k I m n$}

\section{1- \\ 9.42- $6.56-$ \\ 4.36-





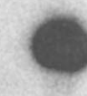

.

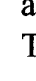

to lack a 2.5 -kb segment corresponding to a region that normally encodes the qacA antiseptic and disinfectant resistance gene on pSK1 family plasmids $[20,30]$.

\section{Discussion}

Gentamicin-resistant $S$. aureus strains were first detected in Australian hospitals in the mid-1970s [7] and in all isolates examined from that time until 1980, the determinant for $\mathrm{GmTmKm}{ }^{\mathrm{r}}$ was shown to be encoded by either the composite transposon $\mathrm{Tn} 4001$ or a Tn4001-like element, both located exclusively on the chromosome [16]. However, in most epidemic $\mathrm{GmTmKm}^{\mathrm{r}}$ strains of $S$. aureus isolated in Australia during and after $1980, \mathrm{GmTmKm}^{\mathrm{r}}$ was encoded by Tn 4001 on members of the pSK1 family of plasmids $[8,11,17]$. It has been suggested that $\operatorname{Tn} 4001$ transposed from the chromosome to a $\mathrm{GmTmKm}^{\mathrm{s}}$ member of the pSK1 family of plasmids, such as pSK7, producing a plasmid equivalent to pSK1 $[8,16,30]$. As Tn 4001 is inserted at an identical site in all members of the pSK1 family examined, transposition of Tn4001 to a family member probably occurred only once with structural differences between the various plasmids evolving later $[16,30]$.

Results of the present study similarly show that $\mathrm{GmTmKm}^{\mathrm{r}}$ S. aureus strains isolated in UK hospitals between 1975 and 1980 carry $\operatorname{Tn} 4001$ or the $\operatorname{Tn} 4001$ like element exclusively on the chromosome. One of the strains included in this study, S. aureus SK3715, was one of the first reported $\mathrm{GmTmKm}^{\mathrm{r}} S$. aureus strains isolated in the UK [2]. This strain, and two other UK strains, SK3718 and SK3738 isolated in 1976 and 1980, respectively, appear to carry the same chromosomal Tn4001-like element as that seen in some of the first $\mathrm{GmTmKm}^{\mathrm{r}}$ strains isolated in Australia [16]. The copies of $\mathrm{Tn} 4001$ and the Tn4001-like elements carried by these UK strains were located at various chromosomal sites, suggesting that they have arisen by independent insertion events and supporting the notion that, like Tn4001 [11], the

Previous reports have suggested that some epidemic $\mathrm{GmTmKm}^{\mathrm{r}}$ strains present in UK hospitals in the 1980s could carry Tn 4001 on a pSK1-like plasmid [25-27]. In one of these studies [25], most $\mathrm{GmTmKm}^{\mathrm{r}} S$. aureus strains isolated from the London Hospital and the Royal Free Hospital, London, during 1983 and 1984, carried plasmids which, from restriction analysis, appear to belong to the pSK1 family. The resistance properties and plasmid profiles of these UK epidemic strains indicated that they are probably identical to, and hence share a clonal origin with, epidemic strains from Australian hospitals [25-27]. In contrast to these epidemic strains, five of six strains isolated between 1980 and 1985 from various UK hospitals and examined in the present study encoded
Fig. 4. Autoradiograph of whole-cell $S$. aureus DNA cleaved with EcoRI and hybridised with an $\alpha-{ }^{32} \mathrm{P}$ nicktranslated probe consisting of the 1.3-kb HindII-Taq I fragment of Tn4001. Fragments were separated by electrophoresis on an agarose $1.0 \% \mathrm{w} / \mathrm{v}$ gel and then transferred to nitrocellulose for hybridisation. Lanes a-n contain DNA from the same strains as those shown in Fig.1. Fragment sizes (in $\mathrm{kb}$ ) of co-electrophoresed HindIII-cleaved $\lambda$ virus DNA are shown on the left. 
the Tn4001 $\mathrm{GmTmKm}^{\mathrm{r}}$ determinant on the chromosome. Only S. aureus SK3763, isolated in 1985, carried Tn4001 located on a pSK1-like plasmid, pSK575. This plasmid was very similar to the pSK1-family plasmid, pSK4, isolated from Australian strains of $S$. aureus (Fig. 2).

The retrospective molecular analysis of UK hospital strains indicates that the pattern of emergence of $\mathrm{GmTmKm}^{\mathrm{r}}$ in Australian and UK $S$. aureus strains is very similar. All strains examined from both countries from the mid-1970s until 1980 carry Tn4001 or the Tn4001-like element at various chromosomal sites. It is possible that chromosomal integration of these elements provided an opportunity for stabilisation of $\mathrm{GmTmKm}^{\mathrm{r}}$ in $S$. aureus populations following transfer of a Tn4001-carrying plasmid from an unidentified donor species. Furthermore, it seems likely that Tn4001 and its derivatives have been exclusively responsible for the spread of gentamicin resistance among $S$. aureus strains in the UK and Australian hospitals.

We thank Dr R. R. Marples for generously providing the collection of UK $S$. aureus strains during a period when one of us (R.A.S.) was working in the laboratory of Professor K. G. H. Dyke, Microbiology Unit, Department of Biochemistry, University of Oxford. This work was supported in part by Project Grants from the National Health and Medical Research Council (Australia).

\section{References}

1. Soussy CJ, Bouanchaud DH, Fouace J, Dublanchet A, Duval J. A gentamicin resistance plasmid in Staphylococcus aureus Ann Microbiol 1975; 126B: 91-94.

2. Porthouse A, Brown DFJ, Smith RG, Rogers T. Gentamicin resistance in Staphylococcus aureus. Lancet 1976; 1: 20-21.

3. Shanson DC, Kensit JC, Duke R. Outbreak of hospital infection with a strain of Staphylococcus aureus resistant to gentamicin and methicillin. Lancet 1976; 2: 1347-1378.

4. Speller DCE, Raghunath D, Stephens M et al. Epidemic infection by a gentamicin-resistant Staphylococcus aureus in three hospitals. Lancet 1976; 1: 464-466.

5. Vogel L, Nathan C, Sweeney HM, Kabins SA, Cohen S. Infections due to gentamicin-resistant Staphylococcus aureus strain in a nursery for neonatal infants. Antimicrob Agents Chemother 1978; 13: 466-472.

6. McGowan JE, Terry PM, Huang T-SR, Houk CL, Davies J. Nosocomial infections with gentamicin-resistant Staphylococcus aureus: Plasmid analysis as an epidemiologic tool. $J$ Infect Dis 1979; 140: 864-872.

7. Perceval A, McLean AJ, Wellington CV. Emergence of gentamicin resistance in Staphylococcus aureus. Med $J$ Aust 1976; 2: 74

8. Gillespie MT, May JW, Skurray RA. Antibiotic susceptibilities and plasmid profiles of nosocomial methicillin-resistant Staphylococcus aureus: a retrospective study. J Med Microbiol 1984; 17: 295-310.

9. Jaffe HW, Sweeney HM, Weinstein RA, Kabins SA, Nathan C, Cohen S. Structural and phenotypic varieties of gentamicin resistance plasmids in hospital strains of Staphylococcus aureus and coagulase-negative staphylococci. Antimicrob Agents Chemother 1982; 21: 773-779.

10. Ubukata K, Yamashita N, Gotoh A, Konno M. Purification and characterization of aminoglycoside-modifying enzymes from Staphylococcus aureus and Staphylococcus epidermidis. Antimicrob Agents Chemother 1984; 25: 754-759.
11. Lyon BR, May JW, Skurray RA. Tn4001: a gentamicin and kanamycin resistance transposon in Staphylococcus aureus. Mol Gen Genet 1984; 193: 554-556.

12. Lyon BR, Gillespie MT, Byrne ME, May JW, Skurray RA Plasmid-mediated resistance to gentamicin in Staphylococcus aureus: the involvement of a transposon. $J$ Med Microbiol 1987; 23: $101-110$.

13. Lyon BR, Gillespie MT, Skurray RA. Detection and characterization of IS256, an insertion sequence in Staphylococcus aureus. J Gen Microbiol 1987; 133: 3031-3038.

14. Byrne ME, Rouch DA, Skurray RA. Nucleotide sequence analysis of IS256 from the Staphylococcus aureus gentamicintobramycin-kanamycin-resistance transposon Tn4001. Gene 1989; 81: $361-367$

15. Rouch DA, Byrne ME, Kong YC, Skurray RA. The aacA$a p h D$ gentamicin and kanamycin resistance determinant of Tn4001 from Staphylococcus aureus: expression and nucleotide sequence analysis. J Gen Microbiol 1987; 133: 3039-3052.

16. Gillespie MT, Lyon BR, Messerotti LJ, Skurray RA. Chromosome- and plasmid-mediated gentamicin resistance in Staphylococcus aureus encoded by Tn4001. J Med Microbiol 1987; 24: $139-144$.

17. Lyon BR, May JW, Skurray RA. Analysis of plasmids in nosocomial strains of multiple-antibiotic-resistant Staphylococcus aureus. Antimicrob Agents Chemother 1983; 23: 817-826.

18. Lyon BR, Iuorio JL, May JW, Skurray RA. Molecular epidemiology of multiresistant Staphylococcus aureus in Australian hospitals. J Med Microbiol 1984; 17: 79-89.

19. Paulsen IT, Firth N, Skurray RA. Resistance to antimicrobial agents other than $\beta$-lactams. In: Crossley KB, Archer GL (eds) The staphylococci in human disease. New York, Churchill Livingstone. 1997: 175-212.

20. Rouch DA, Cram DS, DiBerardino D, Littlejohn TG, Skurray RA. Efflux-mediated antiseptic resistance gene qacA from Staphylococcus aureus: common ancestry with tetracyclineand sugar-transport proteins. Mol Microbiol 1990; 4: 2051 2062.

21. Paulsen IT, Brown MH, Littlejohn TG, Mitchell BA, Skurray RA. Multidrug resistance proteins QacA and QacB from Staphylococcus aureus: membrane topology and identification of residues involved in substrate specificity. Proc Natl Acad Sci USA 1996; 93: 3630-3635.

22. Tennent JM, Young H-K, Lyon BR, Amyes SGB, Skurray RA Trimethoprim resistance determinants encoding a dihydrofolate reductase in clinical isolates of Staphylococcus aureus and coagulase-negative staphylococci. $J$ Med Microbiol 1988; 26: $67-73$

23. Rouch DA, Messerotti LJ, Loo LS, Jackson CA, Skurray RA. Trimethoprim resistance transposon Tn4003 from Staphylococcus aureus encodes genes for a dihydrofolate reductase and thymidylate synthetase flanked by three copies of IS257. Mol Microbiol 1989; 3: 161-175.

24. Gillespie MT, Lyon BR, Skurray RA. Structural and evolutionary relationships of $\beta$-lactamase transposons from Staphylococcus aureus. J Gen Microbiol 1988; 134: 2857-2866.

25. Townsend DE, Ashdown N, Bolton S et al. The international spread of methicillin-resistant Staphylococcus aureus. J Hosp Infect 1987; 9: 60-71.

26. Cookson BD, Phillips I. Epidemic methicillin-resistant Staphy lococcus aureus. J Antimicrob Chemother 1988; 21 Suppl C. $57-65$.

27. Jordens JZ, Hall LMC. Chromosomally-encoded gentamicin resistance in 'epidemic' methicillin-resistant Staphylococcus aureus: detection with a synthetic oligonucleotide probe. $J$ Antimicrob Chemother 1989; 23: 327-334.

28. Sambrook J, Fritsch EF, Maniatis T. Molecular cloning: a laboratory manual, 2nd edn. Cold Spring Harbor, NY, Cold Spring Harbor Laboratory Press. 1989

29. Byrne ME, Gillespie MT, Skurray RA. Molecular analysis of a gentamicin resistance transposonlike element on plasmids isolated from North American Staphylococcus aureus strains. Antimicrob Agents Chemother 1990; 34: 2106-2113.

30. Skurray RA, Rouch DA, Lyon BR et al. Multiresistant Staphylococcus aureus: genetics and evolution of epidemic Australian strains. J Antimicrob Chemother 1988; 21 Suppl C: $19-38$. 